\title{
Congenital obstructive emphysema of the left lung associated with a mediastinal lymphatic cyst
}

\author{
DWK MAN, ST DONELL, F RAAFAT, HB ECKSTEIN \\ From the Departments of Paediatric Surgery and Histopathology, Hospital for Sick Children, Great Ormond \\ Street, London
}

Congenital obstructive emphysema is an uncommon paediatric condition affecting usually a single lobe, occasionally multiple lobes bilaterally, and only rarely a whole lung. This case report describes a neonate with congenital obstructive emphysema of the left lung and an associated lymphatic cyst compressing the left main bronchus, who presented two hours after birth with severe respiratory distress and was treated successfully by pneumonectomy.

\section{Case report}

A $3.36 \mathrm{~kg}$ girl was born to a 24 year old mother at term by normal vaginal delivery. The baby initially failed to breathe spontaneously. The apgar score was 7 at both 1 and 5 minutes. At 2 hours she had failed to feed and was dusky in colour. At 3 hours, with no improvement on pharyngeal suction, she was placed in a head box with $30 \%$ oxygen. At $4 \frac{1}{2}$ hours she was transferred to the Hospital for Sick Children, when a left sided diaphragmatic hernia was suspected on a chest radiograph.

Physical examination showed the baby to be tachypnoeic and mildly cyanosed. Both the trachea and the apex beat were deviated to the right. The left chest was hyperresonant with diminished air entry. Air entry on the right was normal. The heart sounds were normal and there were no murmurs. The abdomen was slightly distended, with the liver and spleen just palpable.

A chest radiograph (fig 1) showed a granulated, mottled, hyperexpanded left lung shifting the heart and mediastinum to the right, and an intact low lying left hemidiaphragm. No compressed lobes were visible. Arterial blood gas estimations with the baby breathing $50 \%$ oxygen gave the following values: $\mathrm{pH} 7 \cdot 18$, carbon dioxide tension $\left(\mathrm{PCO}_{2}\right) 61.9 \mathrm{~mm} \mathrm{Hg}(8.3 \mathrm{kPa}), \mathrm{PO}_{2} 46.5 \mathrm{~mm} \mathrm{Hg}$ (6.2 kPa), and $\mathrm{BE}-7 \cdot 5$. A diagnosis of congenital obstructive emphysema of the left lung was made and the patient was prepared for an elective thoracotomy. Three hours later there was considerable respiratory distress with the following blood gases values: $\mathrm{pH} 7.02, \mathrm{PO}_{2} 109.7 \mathrm{~mm} \mathrm{Hg}(14.6$ $\mathrm{kPa}), \mathrm{PO}_{2} 50.7 \mathrm{~mm} \mathrm{Hg}(6.7 \mathrm{kPa})$, and base excess -7.9 . Emergency thoracotomy was therefore performed.

After endotracheal intubation the baby was anaesthe-

Address for reprint requests: Mr DWK Man, Department of Surgery, Faculty of Medicine, Chinese University of Hong Kong, Shatin, NT, Hong Kong.

Accepted 14 September 1983 tised while breathing spontaneously. The left chest was opened through the 5 th intercostal space. This confirmed the diagnosis of congenital obstructive emphysema of both lobes of the left lung, which was delivered. A $2 \mathrm{~cm}$ thin walled, fluid filled cyst was found arising superiorly from the left main bronchus beneath the aortic arch. The cyst indented but did not extend into the wall of the bronchus. This was aspirated but the left lung did not deflate; the cyst was therefore excised and pneumonectomy was performed.

After operation the baby was ventilated electively for 24 hours, and then assisted with continuous positive airways pressure (CPAP) for two days. With satisfactory blood gas values she was then extubated. The chest radiograph showed the right lung filling the whole of the right hemithorax with the heart and mediastinum on the left. She was discharged home well on the ninth postoperative day.

Microscopically the left lung showed features of congenital emphysema with alveolar rupture (fig $2 a$ ) but there was

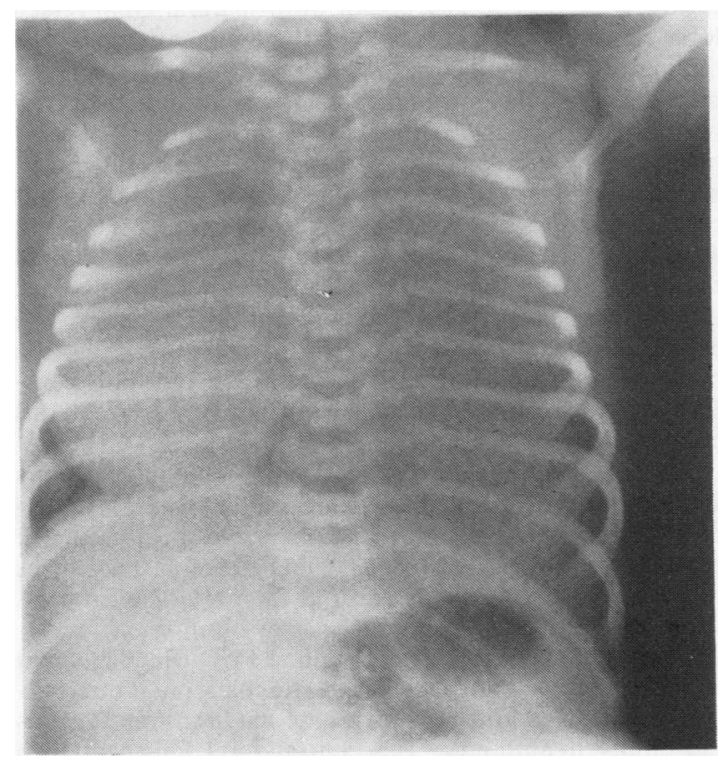

Fig 1 Chest radiograph on admission of the infant about five hours after birth. 

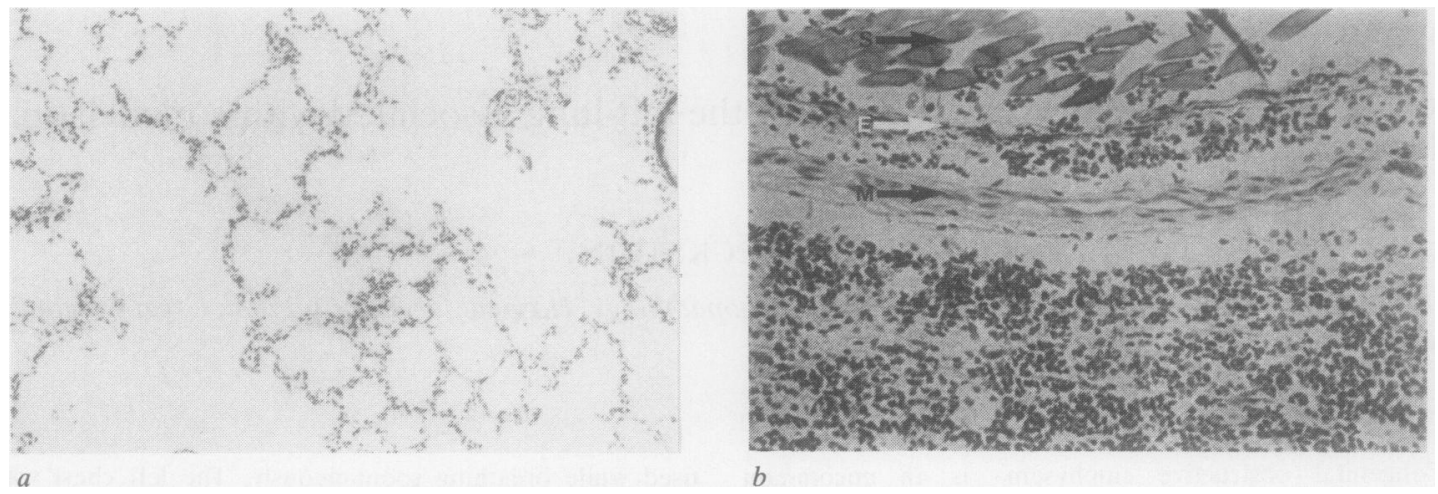

Fig 2 (a) Histological section of the left lung showing emphysema with rupture of the alveolar septae. (b) Histological section of the wall of the lymphatic cyst. $S$-suture material; $E$-endothelium; $M-$ muscle wall. (Haematoxylin and eosin; original magnifications: $\times 125$ for $(a), \times 250$ for $(b)$.)

no evidence of cartilage deficiency in the main bronchus, lobar bronchi, or segmental bronchi. The histological appearance of the cyst was compatible with that of a lymphatic cyst (fig $2 b$ ).

\section{Discussion}

Congenital obstructive emphysema affecting a whole lung is rare and is usually caused by compression of a main bronchus as a result of vascular anomalies.' So far as we are aware there is no report of an association with a mediastinal lymphatic cyst.

The atypical radiological feature of the hazy mottling in the left lung was presumed to be due to incompletely resorbed fluid. The absence of an ipsilateral compressed lobe suggested that the whole lung was affected. The finding of a lymphatic cyst associated with the congenital obstructive emphysema might suggest that they were connected. Air trapping secondary to external bronchial compression, however, usually takes time to exert its full effect ${ }^{2}$ and is therefore precluded by the early presentation in this case. Moreover, removal of the obstruction (that is, aspirating the cyst) should result in immediate deflation of the lung. ${ }^{3}$ The fact that this did not occur here implies lack of elastic recoil in the lung that is not attributable to the chronicity of the obstruction. The implication is that the mediastinal cyst was an incidental finding and that therefore pneumonectomy was an appropriate procedure in this case.

Half of all cases of congenital obstructive emphysema are idiopathic. ${ }^{4}$ Histological examination of the left lung did not identify any aetiological factors, but the presence of ruptured alveoli suggested a primary alveolar defect as rupture does not normally occur at the physiological pressures sustained during spontaneous respiration. ${ }^{5}$

Immediately after pneumonectomy management includes clamping the chest drain and releasing it intermittently to allow a gradual shift of the mediastinum towards the empty hemithorax. The contralateral lung will then slowly expand to occupy the whole hemithorax, thereby preventing a sudden mediastinal shift with its associated respiratory and haemodynamic disturbances. After initial stabilisation respiratory function should normally be adequate.

Long term lung growth after pneumonectomy is a controversial subject. In the normal lung there is a five fold increase in alveolar number in the first year of life, with continued growth until 4 to 11 years of age. ${ }^{6}$ The remaining tissue after pneumonectomy may be expected to show compensatory overgrowth. This has been shown in rabbits? and also in children with congenital diaphragmatic hernias. ${ }^{8}$ Eigen et al,${ }^{9}$ however, after studying a group of children who had had pulmonary resection for congenital lobar emphysema in the neonatal period concluded that the remaining lung tissue grew at the normal rate, leaving the children with mildly reduced respiratory function. Nevertheless, these considerations should not deter the surgeon from performing a lobectomy or pneumonectomy as a life saving procedure in a neonate in severe respiratory distress.

\section{References}

' Stovin PGI. Congenital lobar emphysema. Thorax 1959;14:254-62.

${ }^{2}$ Hamilton LC, Gillespie RW. Congenital hypertrophic emphysema. Am J Roentgenol 1958;80:421-5.

${ }^{3}$ Murray GF. Congenital lobar emphysema. Surg Gynecol Obstet 1967;124:611-25.

${ }^{4}$ Hendren WH, McKee DM. Lobar emphysema of infancy. $J$ Pediatr Surg 1966;1:24-39.

${ }^{5}$ Leopold JG, Gough J. The centrilobular form of hypertrophic emphysema and its relation to chronic bronchitis. Thorax 1957;12:219-35.

- Davis G, Reid L. Growth of alveoli and pulmonary arteries in childhood. Thorax 1970;25:669-81.

' Buhain WJ, Brody JS. Compensatory growth of the lung following pneumonectomy. J Appl Physiol 1973;35:898-902.

${ }^{8}$ Wohl MEB, Griscom MT, Schuster SR, Zwerdling RG, Strieher $D$. Lung growth and function following repair of congenital diaphragmatic hernia. Pediatr Res 1973;7:424.

9 Eigen H. Leman RJ, Waring WW. Congenital lobar emphysema: long term evaluation of surgically and conservatively treated children. Am Rev Respir Dis 1976;113:823-31. 